\title{
Vozes infantis: a caracterização do contraste de vozeamento das consoantes plosivas no Português Brasileiro na fala de crianças de 3 a 12 anos
}

\author{
Maria Teresa Rosangela Lofredo-Bonatto ${ }^{1}$
}

Bonatto MTRL. Vozes infantis: a caracterização do contraste de vozeamento das consoantes plosivas no Português Brasileiro na fala de crianças de 3 a 12 anos [tese]. São Paulo: Pontifícia Universidade Católica de São Paulo - Laboratório Integrado de Análise Acústica e Cognição; 2007.

Os sons obstruintes plosivos são produzidos logo cedo pelas crianças, mas apesar disso, é comum encontrarmos na clínica fonoaudiológica aquelas que apresentam dificuldades para pronunciá-los, principalmente em relação a estabelecer a distinção entre os vozeados e os não-vozeados. Para a produção dos sons vozeados, a literatura fonética explica que o grau de constrição das pregas vocais pode aumentar o nível de obstrução supra-laríngea, igualando-o ao da sub-larínge e como conseqüência dificultar o vozeamento. Para produzir os sons obstruintes vozeados semelhantes aos do adulto, a criança tem que aprender a sincronizar o gesto glotal e oral. Para a investigação acústica da produção dessas plosivas, a literatura aponta várias medidas, dentre elas o Voice Onset Time (VOT), a duração total do segmento correspondente à plosiva e a duração da vogal que a precede ou a sucede.

O objetivo do presente estudo é caracterizar, por meio de uma investigação fonético-acústica, a produção das consoantes plosivas no Português Brasileiro (PB), na fala de crianças de 3 a 12 anos.

Para realizar tal investigação, utilizamos um corpus contendo as seis plosivas do PB, a partir da produção de palavras dissílabas, inseridas em frases-veículo. As crianças foram selecionadas após análise criteriosa e a inspeção do sinal acústico foi realizada na forma de onda e no espectrograma de banda larga. Foram realizadas a extração do VOT e de cada um dos segmentos vocálicos e consonantais a partir do /a/ de "diga", além das palavras-chave, da palavra "baixinho" e da frase completa, começando com a primeira vogal (Ex: "D/i/g/a/p/a/p/a/baixinho").

O corpus das crianças de três anos foi utilizado para a realização do estudo perceptivo com a participação 120 juízes. Quanto aos resultados obtidos, os juízes identificaram as plosivas /b/, /d/ e /g/ como vozeadas quando apresentavam, pelo menos, $53 \%$ de barra de sonoridade. No caso das plosivas /p/, /t/ e /k/, a presença da breathy vowel favoreceu a identificação dessas consoantes como vozeadas e a presença da aspiração não interferiu no julgamento dos juizes para as plosivas não-vozeadas.

Quanto aos resultados da produção, pudemos observar para as plosivas não-vozeadas, tônicas e pós-tônicas, variabilidade nos valores das médias e desvios-padrão elevados para todas as faixas etárias. De forma geral, verificamos que o VOT foi um parâmetro satisfatório para a diferenciação do vozeamento na fala infantil, e esta foi encontrada a partir dos três anos. O VOT não foi específico para diferenciar entre o ponto articulatório das plosivas bilabiais e alveolares.

Os pressupostos teóricos que adotamos, como a Teoria da Fonte e do Filtro (Fant, 1960), a Fonologia Articulatória (FAR - Browman e Goldstein, 1986; 1990; 1992) e a Acústica Articulatória (FAAR - Albano, 2001), a Teoria do Realismo Direto (Fowler, 1986) e a proposta de aquisição do sistema fonológico que Albano (1990) denominou "O Toque de Ouvido", nos permitem afirmar que o contraste de vozeamento esteve presente na produção de fala de todas as crianças. Podemos afirmar, também, que principalmente na produção das crianças de três anos, ocorreu maior latência entre a coordenação dos gestos glotal e articulatório, que foi observada pela grande variabilidade em suas produções em termos de VOT, sendo que as velares revelaram menor variabilidade. Inferimos com base na análise das características espectrográficas e com apoio nos fundamentos teóricos da fonologia gestual (FAR e FAAR) que as crianças pequenas têm dificuldades em interromper um gesto e iniciar outro, provavelmente em função de dificuldades em relação à sobreposição de gestos e com o aumento da idade essa sobreposição passa a ser mais bem realizada.

Tese desenvolvida no Laboratório Integrado de Análise Acústica e Cognição (LIAAC) da Pontifícia Universidade Católica de São Paulo - PUC-SP - Brasil, para obtenção do título de Doutora em Lingüística Aplicada e Estudos da Linguagem, sob a orientação da Profa. Dra. Sandra Madureira.

(1) Doutora, Fonoaudióloga Clínica - São Paulo (SP), Brasil.

Endereço para correspondência: Maria Teresa Rosangela Lofredo-Bonatto. Av. Paulista, 509, $4^{\circ}$ andar, cj 410, Cerqueira César, São Paulo - SP, CEP 01311-910. E-mail: mteresabonatto@uol.com.br 